\title{
Confirmation of Fusarium root rot resistance QTL Fsp-Ps 2.1 of pea under controlled conditions
}

\author{
Clarice J. Coyne ${ }^{1 *}$ DD, Lyndon D. Porter ${ }^{2}$, Gilles Boutet ${ }^{3}, Y_{\text {M Ma }}{ }^{4}$, Rebecca J. McGee ${ }^{5}$, Angélique Lesné3 \\ Alain Baranger ${ }^{3}$ and Marie-Laure Pilet-Nayel ${ }^{3}$
}

\begin{abstract}
Background: Dry pea production has increased substantially in North America over the last few decades. With this expansion, significant yield losses have been attributed to an escalation in Fusarium root rots in pea fields. Among the most significant rot rotting pathogenic fungal species, Fusarium solani fsp. pisi (Fsp) is one of the main causal agents of root rot of pea. High levels of partial resistance to Fsp has been identified in plant genetic resources. Genetic resistance offers one of the best solutions to control this root rotting fungus. A recombinant inbred population segregating for high levels of partial resistance, previously single nucleotide polymorphism (SNP) genotyped using genotyping-by-sequencing, was phenotyped for disease reaction in replicated and repeated greenhouse trials. Composite interval mapping was deployed to identify resistance-associated quantitative trait loci (QTL).
\end{abstract}

Results: Three QTL were identified using three disease reaction criteria: root disease severity, ratios of diseased vs. healthy shoot heights and dry plant weights under controlled conditions using pure cultures of Fusarium solani fsp. pisi. One QTL Fsp-Ps 2.1 explains 44.4-53.4\% of the variance with a narrow confidence interval of $1.2 \mathrm{cM}$. The second and third QTL Fsp-Ps3.2 and Fsp-Ps3.3 are closely linked and explain only 3.6-4.6\% of the variance. All of the alleles are contributed by the resistant parent PI 180693.

Conclusion: With the confirmation of Fsp-Ps 2.1 now in two RIL populations, SNPs associated with this region make a good target for marker-assisted selection in pea breeding programs to obtain high levels of partial resistance to Fusarium root rot caused by Fusarium solani fsp. pisi.

Keywords: Pisum sativum L., Quantitative trait loci, Fusarium solani fsp. pisi

\section{Background}

Dry pea (Pisum sativum L.) production has increased substantially in the US since 2004 to 0.5 million hectares, primarily in the northern tier states of North $\mathrm{Da}$ kota and Montana [1] and in Canada since the turn of the century to 1.7 million hectares in 2016 [2]. The increase of dry pea cultivation in short rotation with cereal crops has been associated with an increase in root rot incidence in in North America [3, 4], Europe [5, 6] and New Zealand [7].

\footnotetext{
* Correspondence: clarice.coyne@ars.usda.gov

1 USDA-ARS Plant Germplasm Introduction \& Testing Research, Washington

State University, Pullman, WA 99164, USA

Full list of author information is available at the end of the article
}

Root rots impose an important biotic stress on pea production world-wide [8]. Pathogens associated with the root disease complex of pea, recently reviewed in Tran et al. [9], include Aphanomyces euteiches, Fusarium species, Phoma pinodella, Didymella pinodes, Pythium spp., Thielaviopsis basicola and Rhizoctonia solani. Kerr [10] was first to note the complexity of root pathogens in the U.S. on pea, albeit with a shorter list of four taxa. Of note, the Fusarium species pathogenic on pea are particularly extensive containing 12 species [11]. $F$. solani $\mathrm{f}$. sp. pisi $(F s p), F$. acuminatum, $F$. avenaceum, $F$. culmorum, F. graminearum, F. sambucinum, F. equiseti, F. oxysporum, F. poae, F. redolens, F. sporotrichioides and $F$. tabacinum were found pathogenic to varying

(c) The Author(s). 2019 Open Access This article is distributed under the terms of the Creative Commons Attribution 4.0 International License (http://creativecommons.org/licenses/by/4.0/), which permits unrestricted use, distribution, and reproduction in any medium, provided you give appropriate credit to the original author(s) and the source, provide a link to the Creative Commons license, and indicate if changes were made. The Creative Commons Public Domain Dedication waiver (http://creativecommons.org/publicdomain/zero/1.0/) applies to the data made available in this article, unless otherwise stated. 
degrees on pea $[5,11]$. In North America, two species have been identified as the most serious production constraints, Fsp and $F$. avenaceum $[3,5,11-13]$ as determined by field surveys, virulence tests and accompanying confirmation of the species using molecular tools [3, 14]. $F$. avenaceum is the dominant species under reduced or no-tillage practices as it survives on the preceding crop residue $[4,5]$ and dominates in the northern plains of North America [3, 12]. However, the importance of both species varies by year [12]. Fsp is the dominant pathogen in the Pacific Northwest corresponding with mostly conventional tillage used in pea production $[13,15]$.

Fsp has been a troublesome pathogen in pea production since its first report in the U.S. in 1918 [16]. Immunity is unknown [13, 17-19] and the quantitative nature of partial resistance is well described [20, 21]. Genetic resistance to Fusarium root rot (FRR) is a very promising solution as many genetic resources with high levels of partial resistance to Fsp are available for breeding [13, 17-19]. However, the genetics of the quantitative partial resistance is little studied with just two QTL reports published for Fsp [22, 23].

A field study first identified one QTL for Fsp [23]. Based on parental lines with multiple root rot resistances released by Kraft [24], recombinant inbred line populations were developed to study pea root rot resistances with the ultimate goal of developing useful markers for molecular breeding programs $[6,25]$. Using one of these RIL populations (DSP $\times$ 90-2131), five QTL were identified for $F s p$ resistance using a linkage map based primarily on SSRs associated with the phenotypic disease expression of lines to Fsp over 3 years of field evaluations in a FRR nursery in Prosser, WA [22]. One QTL identified, Fsp-Ps7.1, was in common with Feng et al. [23]. Field disease nurseries have the confounding factor of potentially other root pathogens being present in the soil and the field disease pressure may be variable across the landscape, which is challenging to control experimentally. The objective of this study was to determine QTL associated with high levels of partial resistance to Fsp in a second RIL population (Baccara $\times$ PI 180693) under controlled conditions using a higher density SNP-based linkage map called "BP-Duarte" [26].

\section{Methods}

\section{Plant material}

The mapping population was $178 \mathrm{~F}_{8}$-derived recombinant inbred lines from the cross of the cultivar 'Baccara' (susceptible) and PI 180693 (partially resistant) [25]. Baccara is a semi-dwarf, semi-leafless (afila) dry pea cultivar with a clear seed coat, round seeds and white flowers (Florimond-Desprez, France, registered in 1992). PI 180693, a cultivar 'Hohenheimer Pink-Flowered' from Germany [27] is one of the multiple-pathogen resistant parents also used by Kraft [24] to develop multiple root disease resistance germplasm and is tall, with normal leaves, pigmented seed coat, round seed and pink flowers.

\section{Greenhouse phenotyping}

The screening procedure of Bodah et al. [28] was followed using the same mix in each test of an equal mix of three Fsp isolates (Fs 02, Fs 07 and Fs 09) isolated from infected pea roots collected in the Palouse Region of Washington and Idaho, USA. Briefly, the single-spored isolates were identified as Fsp using partial translation elongation factor $1-a$ sequences [14]. Isolates were grown for inoculum production on pentachloronitrobenzene (PCNB) [29] agar then transferred to Kerr's media [10] and incubated six days. Spores were collected by centrifugation and resuspended in sterile deionized water $\left(\mathrm{sdH}_{2} \mathrm{O}\right)$ and diluted to $1 \times 10^{6}$ spores $/ \mathrm{ml}$ water. Seeds of each genotype were surface disinfested with a $10 \%$ bleach solution, rinsed in $\mathrm{sdH}_{2} \mathrm{O}$ and soaked for $16 \mathrm{~h}$ in either the spore suspension of Fsp isolates or in $\mathrm{sdH}_{2} \mathrm{O}$ for the non-inoculated control, then planted in perlite in containers (Conetainer, $0.25 \mathrm{~L}$ volume, Stuewe and Sons Inc.). The experimental design was a split-plot design, the main plot (test $=3$ ) was the environment factor, the subplots $(n=2)$ were the lines, with five or six randomized single plant replicates per line per test. Three tests were used in this study. Both Test 1 and 2 included the whole population, 178 lines and Test 3 included 89 lines. Plants were irrigated as needed, a 12-h photoperiod was maintained and greenhouse temperatures were set at $29.4^{\circ} \mathrm{C}$ during the day and $23.9^{\circ} \mathrm{C}$ at night.

The disease evaluation values were taken similar to Bodah et al. [28]. Root disease severity (RDS), plant height, and shoot dry weights were recorded 25 days after planting. RDS was assigned based on a visual scale from 0 to 6 adapted from Hance et al. [30]; where: $0=$ no diseases symptoms; 1 = small hypocotyl lesions; 2 = lesions coalescing around epicotyls and hypocotyls; $3=$ lesions starting to spread into the root system with some root tips infected; 4 = epicotyl, hypocotyl and root system almost completely infected and limited white, uninfected tissue visible; $5=$ completely infected root; and $6=$ plant failed to emerge. Each genotype was evaluated in two to three separate tests (Additional file 1). Scores of two surrogate traits were recorded of shoot dry weights (weight loss) and plant heights (height loss) between inoculated plants and non-inoculated plants similar to Bodah et al. [28] where $1=$ greater than $100 \%$ normal growth; $2=76$ to $100 \%$ of normal growth; $3=51$ to $75 \%$ of normal growth; $4=26$ to $50 \%$ of normal growth and $5=0$ to $25 \%$ of normal growth.

\section{Phenotypic data analysis}

Data was analyzed as three tests with two methods. First, ordinal logistic regression, a statistical analysis method 
that can be used to model the relationship between an ordinal response variable and one or more explanatory variables [31]. An ordinal variable is a categorical variable for which there is a clear ordering of the category levels. Ordinal logistic regression is an extension of logistic regression where the logit (i.e. the log odds) of a binary response is linearly related to the independent variables. The output of an ordinal logistic regression will contain an intercept for each level of the response except one, and a single slope for each explanatory variable pooled across tests for RDS, plant weight and plant height loss. Ordinal logistic regression was applied with fixed effects for lines and environments using $\mathrm{R}$ [32] (Additional file 2). The trait data were also analyzed by analysis of variance (ANOVA) using the mixed linear model (MIXED) procedure with genotype as fixed effect and environment as random effect in SAS University Edition [33]. The statistical model is $Y_{i j}=\beta_{0}+\beta_{1} x_{i}+$ $u_{1} z_{j}+\varepsilon_{i j}$, where $Y_{i j}$ is the response variable, $\beta_{O}$ is the overall mean, $\beta_{1}$ is the genotype effect, $u_{1}$ is environmental effect, and $\varepsilon_{i j}$ is the effect from errors terms. The broad-sense heritability $\left(H^{2}\right)$ was calculated for each trait as $H^{2}=\sigma_{\mathrm{G}}{ }^{2} /\left[\sigma_{\mathrm{G}}{ }^{2}+\left(\sigma_{\mathrm{GE}}{ }^{2} / e\right)+\sigma_{\mathrm{e}}{ }^{2} / r e\right]$, where $\sigma_{\mathrm{G}}{ }^{2}=$ genotypic variance, $\sigma_{\mathrm{GE}}{ }^{2}=$ variance due to interaction between genotype and environment, $\sigma_{\mathrm{e}}{ }^{2}=$ error variance, $e=$ number of environments, $r=$ number of replicates. The variance components were calculated by SAS PROC MIXED with all the effects considered as random effects. PROC UNIVARIATE option of SAS was used to generate summary statistics including skewness and kurtosis [33]. Pearson correlation coefficients among the traits were calculated using SAS PROC CORR.

QTL analysis.

The BP-Duarte linkage map [26] was comprised of 914 markers covering $1073 \mathrm{cM}$ on seven linkage groups (LG) and used genotyping data obtained from SSRs [25] and cDNA derived SNPs [34] markers on 'Baccara' $x$ 'PI180693' 178 RIL population. The Baccara x PI180693 map was from one of the four RIL populations used to build the composite genetic map described in Duarte et al. [34]. The linkage map included 701 SNPs identified from transcriptome sequencing and derived from a Goldengate assay [34], as well as 179 SSRs and 35 other markers (RAPDs, specific PCRs, morphological genes) used in the initial version of the genetic map established from this population [25]. Composite interval mapping (CIM) implemented in QTLCartographer 2.5 software was used to identify significant QTL using mean scores for root disease severity, disease plant height (control vs inoculated), and disease plant weight (control vs inoculated) [35]. Significant LOD threshold was set to 2.8 using Doerge and Churchill's [36] test of 1000 permutations before CIM. Settings for CIM included QTLCartographer Model 6 (default) except for selection of a walk speed of $2 \mathrm{cM}$ and the forward and backward regression method $(P<0.1)$. QTL were declared exceeding the LOD threshold and defined with the range of \pm 1 LOD (95\% confidence interval). MapChart was used to draw the linkage map and QTL locations [37].

\section{Results}

\section{RIL population root rot evaluation}

The RIL population of 178 lines was evaluated for reaction to three isolates of Fsp under controlled conditions and displayed transgressive segregation for both increased susceptibility and increased resistance over the two parental lines as measured by the three disease response traits (Fig. 1, Table 1). The parental reaction fit the expected response for disease severity and plant weight loss, but the parents did not differ for plant height loss (Table 1). Moderate skewness and kurtosis were noted for the three disease scores. Mean disease ratings are skewed towards susceptibility (Fig. 1). This is due to the non-emergence of treated seed where those susceptible lines receive a disease severity score of 6 , plant weight loss and height loss are scored 5. Using ANOVA, the RILs were significantly different in all the traits (Table 2). In terms of environmental effects, there were no significant differences in all traits $\left(P_{\text {disease severity }}\right.$ $=0.19, P_{\text {plant weight }}=0.21$, and $\left.P_{\text {plant height }}=0.20\right)$ using the mixed linear model frequently employed in QTL studies. The environment (test) was significant using ordinal logistic regression for RDS and plant weight loss (Additional file 2). Genotype by environment interaction also had a significant effect (Table 2). All three traits are highly and significantly correlated (Table 3). Broad-sense heritability was high for root disease severity but on the low side for plant height loss and plant weight loss (Table 1) reducing their value as surrogate traits.

\section{QTL for root rot resistance}

Three significant QTL were identified for partial resistance to FRR using the three traits measured with the three alleles from the resistant parent PI 180693 (Table 4). Fsp-Ps2.1 is the strongest QTL with high LOD peaks (25.3-32.4) explaining 44.4 to $53.4 \%$ of the variance for resistance and identified with all three traits. The position of the QTL is the same for RDS and the surrogate traits weight/height loss and the LOD-1 interval is relatively small $(1.2 \mathrm{cM})$. The second and third QTL Fsp-Ps3.2 and Fsp-Ps3.3 are closely linked, their LOD peaks are just above the LOD cutoff of 2.8, explain much less of the variance, 3.6 to $4.6 \%$ and the allele effects are small (Additional file 3). SNP marker detail for each QTL identified is included in Additional file 3. A figure of the linkage groups of non-redundant markers with QTL locations and the LOD intervals (LOD peak \pm 1 and \pm 2 ) is presented in Additional file 4 . 

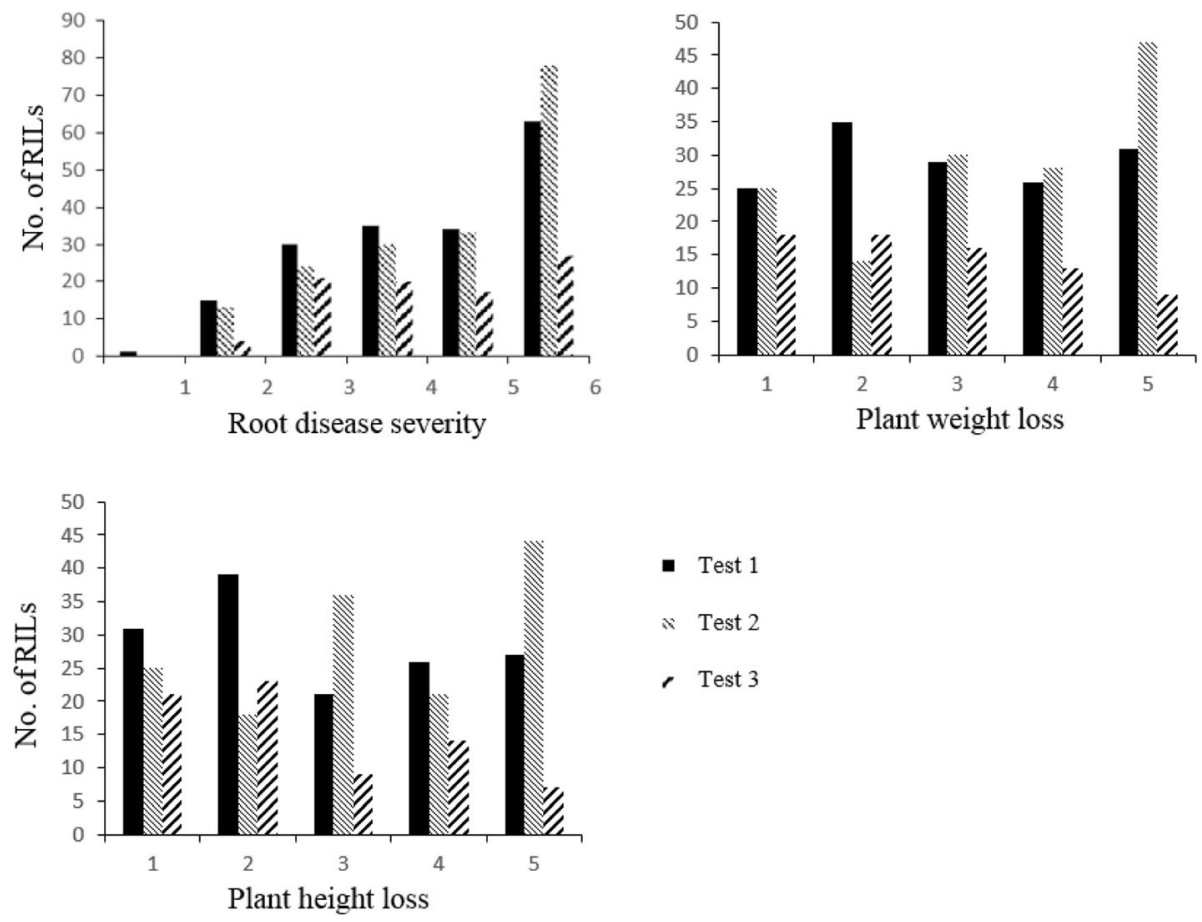

$\begin{array}{ll}\text { - } & \text { Test } 1 \\ \text { N } & \text { Test } 2 \\ \text {, Test } 3\end{array}$

Fig. 1 Frequency histograms of disease severity, plant weight loss and plant height loss scores

\section{Discussion}

Denser pea linkage maps using genotyping-by-sequencing technologies have enabled localizing significant disease resistance QTL to smaller regions giving the prospect of fine mapping and eventual cloning of the underlying resistance genes higher probabilities (e.g. [38]; review [39]). Prior to determining the causal gene(s), the use of SNPs allows the development of breeder friendly markers using marker systems such as KASP [40]. Here we report a significant QTL Fsp-Ps2.1 that explains up to $53 \%$ of the variance and has a small confidence interval. This QTL can be used in plant breeding programs to increase the level of partial resistance to Fsp. We hypothesize the QTL Fsp-Ps2.1 is the same as reported from a field study of another RIL population [22] and we assigned the same name in this report. This is based on comparative mapping between the two RIL populations using common SSR markers, a common parent (PI 180693) in the pedigree of 90-2131, and the similar high variance of resistance explained. Finer

Table 1 Statistical summary of the traits for the parents, the RILs and calculated broad-sense heritabilities based on a mixed linear model

\begin{tabular}{llllllll}
\hline & PI 180693 & Baccara & \multicolumn{3}{l}{ RILs } & & \\
\cline { 5 - 7 } & Mean & Mean & Mean & CV & Range & $H^{2}$ \\
\hline Root disease severity & 2.7 & 4.4 & 4.2 & 47.0 & $0-6$ & $78.8 \%$ \\
Plant weight loss & 1.4 & 3 & 3.1 & 46.3 & $1-5$ & $46.2 \%$ \\
Plant height loss & 2.4 & 2.6 & 3.0 & 49.1 & $1-5$ & $43.4 \%$ \\
\hline
\end{tabular}

mapping in the previous report's RIL population is necessary to confirm this hypothesis.

In this report's $A A \times a a$ RIL population, $A$ (pigmented flower/anthocyanin pigmentation) maps with the interval of Fsp-Ps2.1 and thus is a potential candidate gene. In Coyne et al. [22] Fsp-Ps2.1 was mapped in the white flower $(a a \times a a)$ cross of DSP $\times 90-2131$ so the location of $A$ was estimated to be distal to one SSR marker. One hypothesis is that the resistance gene(s) responsible for $F s p$-Ps 2.1 effect may not necessarily be $A$ since Fsp-Ps 2.1 was originally identified in that white $(a)$ flowered cross. The white flowered, resistant parent of this RIL population, 90-2131, was derived from a complex cross in

Table 2 ANOVA based on the mixed linear model for root disease severity, plant weight loss and plant height loss scores of the RIL population

\begin{tabular}{llll}
\hline & Source & Z Value & Pr $>$ Z \\
\hline Root disease severity & Genotype & 5.62 & $<0.01$ \\
& Environment (test) & 0.87 & 0.19 \\
& Genotype $\times$ Environment & 4.12 & $<0.01$ \\
Plant weight loss & Genotype & 1.87 & $<0.01$ \\
& Environment (test) & 0.82 & 0.21 \\
& Genotype $\times$ Environment & 5.95 & $<0.01$ \\
Plant height loss & Genotype & 1.78 & $<0.01$ \\
& Environment (test) & 0.84 & 0.20 \\
& Genotype $\times$ Environment & 6.03 & $<0.01$ \\
\hline
\end{tabular}


Table 3 Pearson correlation coefficients between the three traits measured for reaction to both inoculation and water-treated control plants of disease symptoms per se, percentage plant heights and percentage dry weights converted to a 0-6 scale (disease severity) and 1-5 scale (plant height loss and weight loss scores)

\begin{tabular}{lccc}
\hline & Root disease severity & Plant weight loss & Plant height loss \\
\hline Root disease severity & 1.00 & $0.79^{\mathrm{a}}$ & $0.78^{\mathrm{a}}$ \\
Plant weight loss & & 1.00 & $0.93^{\mathrm{a}}$ \\
Plant height loss & & & 1.00 \\
\hline
\end{tabular}

${ }^{\mathrm{a} S i g n i f i c a n t}$ at the 0.001 probability level

which PI 180693 (AA) was the male parent and is resistant to FRR [24]. Kraft may have successfully broken the linkage between Fsp-Ps2.1 and $A$ in white-flowered Fsp resistant lines he released [24, 41, 42]. Alternatively, a different gene(s) for FRR resistance was transferred in those crosses [24, 41, 42]. Fine mapping in both populations will be necessary to test this hypothesis.

The second QTL, Fsp-Ps3.2, is new, distal to the previously reported QTL on linkage group III, Fsp-Ps3.1 [22]. Fsp-Ps3.2 and Fsp-Ps3.3 may harbor weaker resistant alleles as they have low LOD scores and explain less of the variance (up to 4.6\%) than Fsp-Ps3.1 (up to 9.9\%). Fsp-Ps3.2 or Fsp-Ps3.3 may possibly be one of the same QTL for Fsp near the $M$ gene (brown mottling of testa) reported in [30]. However, we were unable to map the $M$ locus as it is not segregating in this report's population to confirm this possibility. Fsp-Ps3.2 may be of more interest for resistance as it was detected with RDS score while Fsp-Ps3.3 may be more linked to tolerance as it was only detected with the surrogate traits of plant weight and height loss. The confidence intervals for both overlap and are large, up to $25.2 \mathrm{cM}$ so it would be more difficult to use in breeding for resistance to Fsp.

Screening larger RIL populations for plant disease resistance in greenhouses necessitates large numbers of replicates and untreated check lines. Physical space limitations and phenotyping capability constraints dictate compromises on the experimental design. The analysis of the ordinal data using ordinal logistic regression was effective for the data analysis. It revealed that the split plot design with line as the subplot was significant so was not the optimum choice (Additional file 2). A better design would be a randomized complete block design with fewer replicates per test when confronted with space limitations. Additionally, to overcome the challenge of limited data collection capability, high-throughput phenotyping platforms may relieve the bottleneck and enable faster and more efficient phenotypic data collection.

As noted in Coyne et al. [22], Fsp-Ps2.1 collocated with the Aphanomyces root rot partial resistance QTL Ae-Ps 2.1 based on sparse common SSR markers from Hamon et al. [25]. Now, using a denser SNP-based linkage map, Fsp-Ps 2.1 clearly collocates with an adjacent QTL, Ae-Ps2.2 [25]. QTL meta-analysis identified MQTL-Ae5/ Ae6 for Aphanomyces at this location provides evidence for the importance of this allele for root rot resistance in pea [43]. Additionally, Fsp-Ps3.2 collocates with Aphanomyces root rot partial resistance QTL Ae-Ps3.1.

Interestingly, strong QTL controlling partial resistance to Fusarium root rot have been reported in other legumes, among which one presented a high broad sense

Table 4 Quantitative trait loci detected for resistance to Fusarium root rot in Baccara $\times$ PI 180693 recombinant inbred lines population using RDS, weight loss and height loss scores

\begin{tabular}{|c|c|c|c|c|c|c|c|c|}
\hline $\mathrm{LG}^{\mathrm{a}}$ & $\begin{array}{l}\text { QTL } \\
\text { name }\end{array}$ & Scoring trait & $\begin{array}{l}\text { Position } \\
(\mathrm{CM})\end{array}$ & $\begin{array}{l}\text { Closest left marker from the } \\
\text { position }\end{array}$ & $\begin{array}{l}\mathrm{LOD}^{\mathrm{b}} \\
\text { peak }\end{array}$ & $\begin{array}{l}\text { LOD-1 support interval } \\
(\mathrm{CM})\end{array}$ & $\begin{array}{l}R^{2} \\
(\%)\end{array}$ & $\begin{array}{l}\text { Additive } \\
\text { effect }^{c}\end{array}$ \\
\hline \multirow[t]{3}{*}{$\|$} & Fsp-Ps2.1 & $\begin{array}{l}\text { Root } \\
\text { disease } \\
\text { severity }\end{array}$ & 49.3 & Ps900203 & 32.4 & 1.2 & 53.4 & 0.92 \\
\hline & Fsp-Ps2.1 & Height loss & 49.3 & Ps900203 & 25.3 & 1.2 & 44.4 & 0.80 \\
\hline & Fsp-Ps2.1 & Weight loss & 49.3 & Ps900203 & 27.9 & 1.2 & 50.5 & 0.83 \\
\hline \multirow[t]{3}{*}{ III } & Fsp-Ps3.2 & $\begin{array}{l}\text { Root } \\
\text { disease } \\
\text { severity }\end{array}$ & 23.5 & Ps900299 & 3.14 & 23.0 & 3.9 & 0.24 \\
\hline & Fsp-Ps3.3 & Height loss & 35.3 & Ps900382 & 3.24 & 16.8 & 4.6 & 0.27 \\
\hline & Fsp-Ps3.3 & Weight loss & 35.3 & Ps900195 & 2.94 & 25.2 & 3.6 & 0.22 \\
\hline
\end{tabular}

Pea linkage group as assigned in [25]

${ }^{\mathrm{b}}$ Logarithm of odds

CEffect of substituting Baccara alleles for PI 180693 alleles at the QTL. A positive sign indicates that QTL alleles increasing the resistance are contributed by the resistant parent PI 180693, whereas a negative sign means resistant alleles are contributed by the susceptible parent Baccara 
heritability. In soybean, one QTL for resistance to $\mathrm{Fu}$ sarium graminearum explained 38.5\% (LOD 23.9) of the phenotypic variance with high $H^{2}$ of 0.79 [44] similar to Fsp-Ps2.1 and our calculated $H^{2}$. A second soybean publication identified a QTL explaining $40.2 \%$ of the variance (LOD 20.3) for resistance to $F$. graminearum [45]. In a common bean study, an important QTL explained 23\% of the variance (LOD 11.5) and a second one with lower percentage of the variance (9\%) was reported [46]. However, narrow sense heritabilites were very low $\left(h^{2}=0.19-0.20\right)$ [46]. In a second bean study, one QTL was identified for FRR explaining just $10 \%$ of the variance (LOD 3.2) [47]. Conversely, in a recent bean study, QTLs for $F$. solani resistance identified 17 QTL related to FRR explaining at most $16 \%$ of the variance (LOD 5.84) [48]. In the closely related legume, lentil, Fusarium root rot was identified as a problem by Hwang et al. [49] and noted as an increasing production constraint [4]. However, no genetic studies on resistance to FRR in lentil have been published to date.

None of the legume root rot resistance genes are known to date (review [39]), however an F-box encoding gene is strongly suggested to be implicated for Aphanomyces resistance in Medicago truncatula [50]. The resistance gene to $F$. graminearum in a non-legume crop has been identified in wheat as a chimeric lectin for head blight but not crown rot resistance[51]. Fsp-Ps2.1 may be an interesting target for determining the gene(s) most responsible for the high levels of partial resistance found in both RILs reported here and in Coyne et al. [22]. Interestingly, using a transgenics approach in pea, four antifungal genes 1-3 $\beta$ glucanase (G), endochitinase (C) (belonging to PR proteins family), polygalacturonase inhibiting proteins PGIPs) (P) and stilbene synthase (V) did not consistently improve disease resistance to $F$. avenaceum in field studies [52] so perhaps Fsp-Ps2.1 is not any of these genes. New genomic tools, innovations in phenotyping and VIGs technology in pea will assist in the determination gene(s) for high levels of partial resistance to Fsp [53-55].

\section{Conclusions}

The confirmation of the important QTL Fsp-Ps2.1 is a step forward in understanding high levels of partial resistance to Fusarium root rot, caused by $F s p$, in pea. The high level of the variance explained and the small confidence interval indicate the SNPs associated with this QTL are a good target for marker assisted breeding. The interval for QTL Fsp-Ps3.2 is too large and would need additional fine mapping to provide informative markers.

\section{Additional files}

Additional file 1: Phenotypic data for the disease severity, plant height loss and plant weight loss scores of the RIL population. (XLSX 69 kb)

Additional file 2: $\mathrm{R}$ code for ordinal logistic regression and ANOVA. (DOCX $16 \mathrm{~kb}$ )

Additional file 3: SNP polymorphism and adjacent sequence of QTLassociated markers reported for disease severity in Table 4. (XLSX 12 kb)

Additional file 4: Linkage map and QTLs. Black box \pm 1 LOD and line bars \pm 2 LOD from peak. (PDF $719 \mathrm{~kb}$ )

\section{Abbreviations}

CIM: composite interval mapping; Fsp: Fusarium solani fsp. Pisi;

QTL: quantitative trait locus; RDS: root disease severity; SNP: single nucleotide polymorphism; SSR: simple sequence repeat

\section{Acknowledgments}

The authors thank Ginny Coffman for technical assistance with the greenhouse experiments and Clément Lavaud for his help in building the genetic map; the greenhouse and experimental device platform of IGEPP for providing and managing equipment for the RIL population production.

\section{Funding}

This research was funded by USDA-ARS CRIS projects 5348 21000-024-00D (LDP, RJM) and 5348-21000-026-00D (CJC), the USA Dry Pea and Lentil Council (USADPLC) Research funds (CJC, RJM, YM), and the French FASO (Le Fonds d'Action Stratégique des Oléoprotéagineux) project "PEAPOL" (GB, MLPN, $\mathrm{AB})$

\section{Availability of data and materials}

All relevant data is contained within this manuscript and its additional files and in cited literature. All the relevant plant materials used in this study are available for research purposes upon written permission from INRA.

\section{Authors' contributions}

LDP, CJC, MLPN initiated and designed the project. LDP conducted the greenhouse experiment, MLPN and AL developed the RILS, MLPN, GB and $A B$ genotyped the RILs and linkage analysis, CJC, YM and RJM performed data analysis for QTL identification, CJC wrote the manuscript with input and edits from LDP, M-LP-N, GB, AB, RJM, YM. All authors read and approved the manuscript.

\section{Ethics approval and consent to participate}

Not applicable.

Consent for publication

Not applicable.

\section{Competing interests}

The authors declare that they have no competing interests.

\section{Publisher's Note}

Springer Nature remains neutral with regard to jurisdictional claims in published maps and institutional affiliations.

\section{Author details}

${ }^{1}$ USDA-ARS Plant Germplasm Introduction \& Testing Research, Washington State University, Pullman, WA 99164, USA. ${ }^{2}$ USDA-ARS Grain Legume Genetics \& Physiology Research, 24106 N. Bunn Road, Prosser, WA 99350, USA. ${ }^{3}$ Institut de Génétique, Environnement et Protection des Plantes, INRA, Agrocampus Ouest, Université Rennes 1, 35650 Le Rheu, France.

${ }^{4}$ Department of Horticulture, Washington State University, Pullman, WA 99164, USA. ${ }^{5}$ USDA-ARS, Grain Legume Genetics \& Physiology Research, Pullman, WA 99164, USA. 


\section{Received: 28 September 2018 Accepted: 28 February 2019} Published online: 12 March 2019

\section{References}

1. USDA NASS, 2018. https://www.nass.usda.gov/. Accessed 11 Sept 2018.

2. FAOSTAT 2018. http://www.fao.org/faostat/en/\#home. Accessed 11 Sept 2018.

3. Zitnick-Anderson K, Simons K, Pasche JS. Detection and qPCR quantification of seven Fusarium species associated with the root rot complex in field pea. Can J Plant Pathol. 2018:40:261-71. https://doi.org/10.1080/07060661.2018. 1429494.

4. Gossen B, Conner R, Chang KF, Pasche JS, McLaren DL, Henriquez MA, et al. Identifying and managing root rot of pulses on the northern Great Plains. Plant Dis. 2016;100:1965-78.

5. Šišić A, Baćanović-Šišić J, Karlovsky P, Wittwer R, Walder F, Campiglia E, et al. Roots of symptom-free leguminous cover crop and living mulch species harbor diverse Fusarium communities that show highly variable aggressiveness on pea (Pisum sativum). PLoS One. 2018;13:0191969. https:// doi.org/10.1371/journal.pone.0191969.

6. Pilet-Nayel ML, Muehlbauer FJ, McGee RJ, Kraft JM, Baranger A, Coyne CJ. Quantitative trait loci for partial resistance to Aphanomyces root rot in pea. Theor Appl Genet. 2002;106:28-39.

7. New Zealand Institute for Plant and Food Research, Gail TimmermanVaughan, personal communication.

8. Kraft JM, Pfleger FL. Compendium of pea diseases and pests (2nd Ed.) American Phytopathological Society, APS Press. 2001. p. 13-14.

9. Tran HS, You MP, Khan TN, Barbetti MJ. Pea black spot disease complex on field pea: dissecting the roles of the different pathogens in causing epicotyl and root disease. Eur J Plant Pathol. 2016;144:595-605.

10. Kerr A. The root rot Fusarium wilt complex of peas. Aust J Biol Sci. 1963;16: 55-69.

11. Chittem K, Mathew FM, Gregoire M, Lamppa RS, Chang YW, Markell SG, et al. Identification and characterization of Fusarium spp. associated with root rots of field pea in North Dakota. Eur J Plant Pathol. 2015;143:641-9.

12. Taheri AE, Chatterton S, Foroud NA, Gossen BD, McLaren DL. Identification and community dynamics of fungi associated with root, crown, and foot rot of field pea in western Canada. Eur J Plant Pathol. 2016;147:489-500. https:// doi.org/10.1007/s10658-016-1017-4.

13. Porter LD, Kraft JM, Grünwald NJ. Release of pea germplasm with resistance combined with desirable yield and anti-lodging traits. J Plant Regist. 2014;8: 191-4.

14. Geiser DM, Jiménez-Gasoc MM, Kang S, Makalowska I, Veeraraghavan N, Ward TJ, et al. Fusarium-ID v. 1.0: a DNA sequence database for identifying Fusarium. Eur J Plant Pathol. 2004:110:473-9.

15. Porter LD, Pasche JS, Chen W, Harveson RM. Isolation, identification, storage pathogenicity tests, hosts, and geographic range of Fusarium solani f. Sp. pisi causing fusarium root rot of pea. Plant Health Prog. 2015;16:136-45.

16. Bisby GR. A Fusarium disease of garden peas in Minnesota. Phytopathology. 1918:8-77.

17. Coyne CJ, Porter LD, Inglis DA, Grünwald NJ, McPhee KE, Muehlbauer FJ. Registration of W6 26740, W6 26743 and W6 26745 pea germplasm resistant to Fusarium root rot. J Plant Regist. 2008;2:137-9.

18. Grünwald NJ, Coffman VA, Kraft JM. Sources of partial resistance to Fusarium root rot in the Pisum core collection. Plant Dis. 2003;87:1197-200.

19. Kraft JM, Roberts DD. Resistance in peas to Fusarium and Pythium root rot. Phytopathology. 1970;60:1814-7.

20. Lockwood JL. Pea introductions with partial resistance to Aphanomyces root rot. Phytopathology. 1960;50:621-4.

21. Muehlbauer FJ, Kraft KM. Evidence of heritable resistance to Fusarium solani f. Sp. pisi and Phythium ultimum in peas. Crop Sci. 1973;3:34-6.

22. Coyne CJ, Pilet-Nayel M-L, McGee RJ, Porter LD, Smykal P, Grünwald NJ. Identification of QTL controlling high levels of partial resistance to Fusarium solani f. Sp. pisi in pea. Plant Breed. 2015;134:446-53.

23. Feng J, Hwang R, Chang KF, Conner RL, Hwang SF, Strelkov SE, et al. Identification of microsatellite markers linked to quantitative trait loci controlling resistance to Fusarium root rot in field pea. Can J Plant Sci. 2011; 91:199-204

24. Kraft JM. Registration of 90-2079, 90-2131 and 90-2322 pea germplasms. Crop Sci. 1992;32:1076

25. Hamon C, Baranger A, Coyne CJ, McGee RJ, Le Goff I, L'Anthoëne V, et al. New consistent QTL in pea associated with partial resistance to
Aphanomyces euteiches in multiple field and controlled environments from France and the United States. Theor Appl Genet. 2011;123:261-81.

26. Boutet $G$, Carvalho SA, Falque M, Peterlongo P, Lhuillier E, Bouchez O, et al. SNP discovery and genetic mapping using genotyping by sequencing of whole genome genomic DNA from a pea RIL population. BMC Genomics. 2016;7:121. https://doi.org/10.1186/s12864-016-2447-2.

27. USDA Grin Global, 2018. https://npgsweb.ars-grin.gov/gringlobal/search.aspx

28. Bodah ET, Porter LD, Chaves B, Dhingra A. Evaluation of pea accessions and commercial cultivars for fusarium root rot resistance. Euphytica. 2016;208: 63-72.

29. Nash SM, Snyder WC. Quantitative estimations by plate counts of propagules of the bean root rot Fusarium in the field soils. Phytopathology. 1962:52:567-71.

30. Hance ST, Grey W, Weeden NF. Identification of tolerance to Fusarium solani in Pisum sativum ssp. elatius. Pisum Genet. 2004;3:9-13.

31. McCullagh P. Regression models for ordinal data. J R Stat Soc B. 1980;42: 109-42.

32. $\mathrm{R}$ Core Team. R: a language and environment for statistical computing. Vienna: R Foundation for Statistical Computing; 2013. www.R-project.org

33. SAS Institute. 2004. The SAS system for Windows. Release 9.1.3. SAS Inst., Cary, NC.

34. Duarte J, Rivière N, Baranger A, Aubert G, Burstin J, Cornet L, et al. Transcriptome sequencing for high throughput SNP development and genetic mapping in pea. BMC Genomics. 2014;15:126.

35. Wang S, Basten CJ, Zeng Z-B. Windows QTL Cartographer 2.5. Raleigh: Department of Statistics, North Carolina State University; 2012. https:// brcwebportal.cos.ncsu.edu/qtlcart/WQTLCart.htm. Accessed 11 Sept 2018.

36. Churchill GA, Doerge RW. Empirical threshold values for quantitative trait mapping. Genetics. 1994;138:963-71.

37. Voorrips RE. MapChart: software for the graphical presentation of linkage maps and QTLs. J Hered. 2002:93:77-8.

38. Barilli E, Cobos MJ, Carrillo E, Kilian A, Carling J, Rubiales DA. High-density integrated DArTseq SNP-based genetic map of Pisum fulvum and identification of QTLs controlling rust resistance. Front Plant Sci 2018;9:167. doi.org/https://doi.org/10.3389/fpls.2018.00167

39. Pilet-Nayel ML, Moury B, Caffier V, Montarry J, Kerlan MC, Fournet S, et al. Quantitative resistance to plant pathogens in pyramiding strategies for durable crop protection. Front Plant Sci. 2017:8:1838. https://doi.org/10. 3389/fpls.2017.01838.

40. Semagn K, Babu R, Hearne S, Olsen M. Single nucleotide polymorphism genotyping using Kompetitive allele specific PCR (KASP): overview of the technology and its application in crop improvement. Mol Breed. 2014;33:1-14.

41. Kraft JM, Silbernagel MK, Muehlbauer FJ. Registration of PH-14-119 and PH91-3 pea germplasm. Crop Sci. 1972;12:399.

42. Kraft JM, Giles RA. Registration of 74SN3, 74SN4, and 74SN5 pea germplasm. Crop Sci. 1976;16:126.

43. Hamon C, Coyne CJ, McGee RJ, Lesné A, Esnault R, Mangin P, et al. QTL metaanalysis provides a comprehensive view of loci controlling partial resistance to Aphanomyces euteiches in four sources of resistance in pea. BMC Plant Biol 2013;13(1):.45. doi.org/https:/doi.org/10.1186/1471-2229-13-45.

44. Acharya B, Lee $S$, Mian MR, Jun TH, McHale LK, Michel AP, Dorrance AE. Identification and mapping of quantitative trait loci (QTL) conferring resistance to Fusarium graminearum from soybean PI 567301B. Theor Appl Genet. 2015;128:827-38.

45. Cheng P, Gedling CR, Patil G, Vuong TD, Shannon JG, Dorrance AE, Nguyen $H T$. Genetic mapping and haplotype analysis of a locus for quantitative resistance to Fusarium graminearum in soybean accession PI 567516C. Theor Appl Genet. 2017;130:999-1010.

46. Hagerty CH, Cuesta-Marcos A, Cregan PB, Song Q, McClean P, Noffsinger S, Myers JR. Mapping Fusarium solani and Aphanomyces euteiches root rot resistance and root architecture quantitative trait loci in common bean Crop Sci. 2015;55:1969-77.

47. Nakedde T, Ibarra-Perez FJ, Mukankusi C, Waines JG, Kelly JD. Mapping of QTL associated with Fusarium root rot resistance and root architecture traits in black beans. Euphytica. 2016;212:51-63.

48. Wang W, Jacobs JL, Chilvers MI, Mukankusi CM, Kelly JD, Cichy KA. QTL analysis of Fusarium root rot resistance in an Andean $\times$ middle American common bean RIL population. Crop Sci. 2018;58:1166-80. https://doi.org/10. 2135/cropsci2017.10.0608.

49. Hwang SF, Howard RJ, Chang KF, Park B, Burnett PA. Etiology and severity of fusarium root rot of lentil in Alberta. Can J Plant Pathol. 1994;16:295-303. 
50. Bonhomme M, André O, Badis Y, Ronfort J, Burgarella C, Chantret N, et al. High-density genome-wide association mapping implicates an F-box encoding gene in Medicago truncatula resistance to Aphanomyces euteiches. New Phytol. 2014;201:1328-42.

51. Rawat N, Pumphrey MO, Liu S, Zhang X, Tiwari VK, Ando K, et al. Wheat Fhb1 encodes a chimeric lectin with agglutinin domains and a poreforming toxin-like domain conferring resistance to Fusarium head blight. Nat Genet. 2016;48:1576-80.

52. Kahlon JG, Jacobsen HJ, Chatterton S, Hassan F, Bowness R, Hall LM, Lack of efficacy of transgenic pea (Pisum sativum L.) stably expressing antifungal genes against Fusarium spp. in three years of confined field trials. GM Crops Food 2018;0:1-19. doi: https://doi.org/10.1080/21645698.2018.1445471.

53. Alves-Carvalho $\mathrm{S}$, Aubert $\mathrm{G}$, Carrère $\mathrm{S}$, Cruaud $\mathrm{C}$, Brochot AL, Jacquin F, et al, Full-length de novo assembly of RNA-seq data in pea (Pisum sativum L.) provides a gene expression atlas and gives insights into root nodulation in this species. Plant J. 2015;84:1-19.

54. Desgroux A, Baudais VN, Aubert V, Le Roy G, de Larambergue H, Miteul H. Comparative genome-wide-association mapping identifies common loci controlling root system architecture and resistance to Aphanomyces euteiches in pea. Front. Plant Sci. 2018;8:2195.

55. Meziadi C, Blanchet S, Geffroy V, Pflieger S. Virus-induced gene silencing (VIGS) and foreign gene expression in Pisum sativum L. using the "one-step" Bean pod mottle virus (BPMV) viral vector. In: Kaufmann M, Klinger C, Savelsbergh A, editors. Functional genomics. Methods in molecular biology, vol. 1654. New York, NY: Humana Press; 2017. p. 311-9.

Ready to submit your research? Choose BMC and benefit from:

- fast, convenient online submission

- thorough peer review by experienced researchers in your field

- rapid publication on acceptance

- support for research data, including large and complex data types

- gold Open Access which fosters wider collaboration and increased citations

- maximum visibility for your research: over $100 \mathrm{M}$ website views per year

At $\mathrm{BMC}$, research is always in progress.

Learn more biomedcentral.com/submissions 